NASA Contractor Report 185132

\title{
Mathematical Modeling and Analysis of Heat Pipe Start-Up From the Frozen State
}

Jong Hoon Jang and Amir Faghri

Wright State University

Dayton, Ohio

and

Won Soon Chang and Edward T. Mahefkey

Wright Research and Development Center

Wright-Patterson AFB, Ohio

August 1989

Prepared for

Lewis Research Center

Under Contract F336 15-88-C-2820

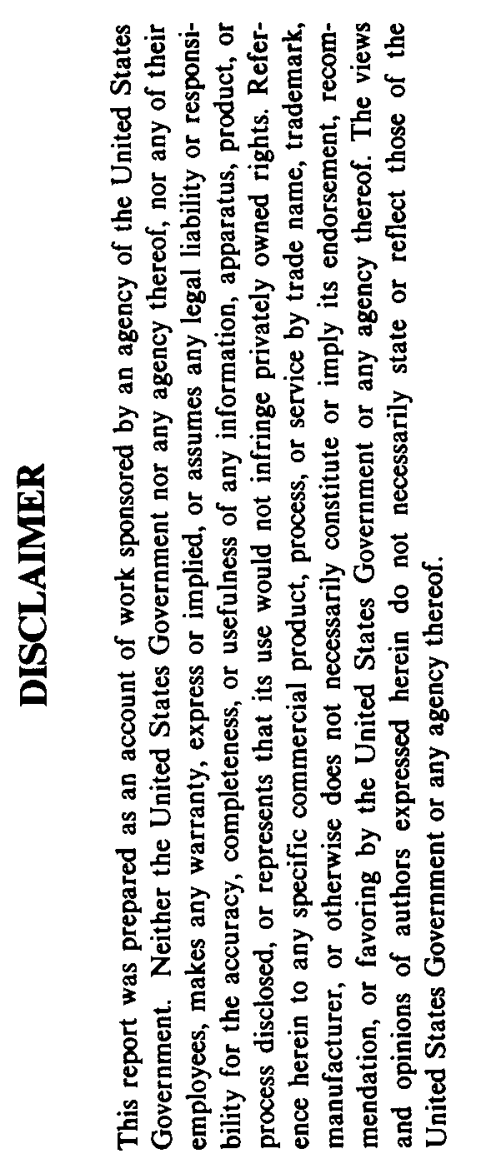

\section{NASก}

National Aeronautics and

Space Administration 


\section{DISCLAIMER}

This report was prepared as an account of work sponsored by an agency of the United States Government. Neither the United States Government nor any agency Thereof, nor any of their employees, makes any warranty, express or implied, or assumes any legal liability or responsibility for the accuracy, completeness, or usefulness of any information, apparatus, product, or process disclosed, or represents that its use would not infringe privately owned rights. Reference herein to any specific commercial product, process, or service by trade name, trademark, manufacturer, or otherwise does not necessarily constitute or imply its endorsement, recommendation, or favoring by the United States Government or any agency thereof. The views and opinions of authors expressed herein do not necessarily state or reflect those of the United States Government or any agency thereof. 


\section{DISCLAIMER}

Portions of this document may be illegible in electronic image products. Images are produced from the best available original document. 


\title{
MATHEMATICAL MODELING AND ANALYSIS OF HEAT PIPE START-UP FROM THE FROZEN STATF
}

\author{
by \\ Jong Hoon Jang ${ }^{+}$and Amir Faghri \\ Department of Mechanical and Materials Engineering \\ Wright State University \\ Dayton, Ohio 45435 \\ and
}

Won Soon Chang and Edward T. Mahefkey

Wright Research and Dereiopment Cenier

Wright-Patterson AFB, OH $\leq 5 \pm 33$

\begin{abstract}
The start-up process of $a$ frozen heat pipe is described and a complete mathematical model for the start-np of the frozen hear pipe is developed based on the existing experimental daia, which is simplified and solved numericaiiy. The two-dimensional transient mociel for the wall and wick is coupled with the one-dimensional transient rodel for the vapor flo when vaporization and conjersation occur at the interiace. A parametric study is periormed to examine the efifect of the boundary specuñcation at the surface of the outer wall on the successiul start-up from the irozen staite. For successful start-ap, the boundary specification at the onter wail suriace must melt the working substance in the condenser beiore ary-out takes place in the evaporator.
\end{abstract}

\section{NOMENCLATURE}

$c_{p} \quad$ specific heat at constart pressure, $J / \overline{k g}-K$

$c_{\mathrm{y}}$ specific heat at constant volume, $\mathrm{J} / \mathrm{kg}-\mathrm{K}$

D diameter of the vapor space, $m$

E total energy of the vapor per unit volume, $\rho\left[c_{v} T_{v}+\right.$ $l / 2\left(\mathrm{U}_{\mathrm{v}}^{2}+\mathrm{v}_{\mathrm{v}}^{2}\right) \mathrm{j}$

f friction coefficient at the wail, $\tau / \rho \mathrm{U}_{v}^{2}$

h enthalpy, J/kg

$h_{c}$ heat transfer coefficient, $W / m^{2}-K$

$\mathrm{h}_{\mathrm{t}}$ latent heat of vaporization, $\mathrm{J} / \mathrm{kg}$

$H_{s \ell}$ latent heat of melting per unit volume, $J / \mathrm{m}^{3}$

$\mathrm{k}$ permeability of the wick structure, $\mathrm{m}^{2}$

$\mathrm{K}$ thermal conductivity, $\mathrm{W} / \mathrm{m}-\mathrm{K}$

\footnotetext{
${ }^{+}$Currently with Sverdrup Technology, Inc., NASA

Lewis Research Center Group, Cleveland, Ohio 44135.
}

-Professor.
L

$\dot{m}_{0}$ rate of evaporation or condensation per unit area;

M molecular weight, $\mathrm{kg} / \mathrm{Kmol}$

n anit outward normal direction

$\mathrm{P}$ pressure, $\mathrm{N} / \mathrm{m}^{2}$

$q$ beat fux, $W / \mathrm{m}^{2}$

$q^{\prime}$ new heat fiux, $W / m^{2}$

$q^{n}$ rew guessed hea: $\mathrm{fux}, W / \mathrm{m}^{2}$

$\mathrm{P}_{\text {Cr }}$ reterence pressure for the Clansius-Clapeyron relationship, $\mathrm{Ni} \mathrm{m}^{2}$

I coordinate in the racial direction

$r_{c}$ effective capillary radius, in

Ip radius of curvature of the meniscus, $m$

$\Delta r \quad$ radial distance between nodes, $m$

$R_{n}$ universal gas constant, KJ/Kmol-K

$R_{v}$ radius of the vapor space, $m$

$R_{w} \quad$ inner radius of the heat pipe wall, $m$

$\$$ interface position in vector, $m$

$t$ time, $s$

$\mathrm{T}$ temperature, $\mathrm{K}$

$T_{c}$ reference temperature for convection, $K$

$T_{c r}$ reference temperature for the Clausins-Clapeyron relationship, $\mathbf{K}$

$T_{m}$ melting temperature, $K$

$T_{r} \quad$ reference temperature for radiation, $K$

$T_{s} \quad$ saturation temperature, $K$

$\mathrm{T}_{\mathrm{j}-1}$ temperature at node $\mathrm{j}-\mathrm{l}$ in the radial direction in the wick region, $K$

$T_{j}$ temperature at last node near liquid-vapor interface in the radial direction in the wick region, $K$

$\mathrm{T}^{*}$ transition temperature, $\mathrm{K}$ 
small finite tempera:ure interral around $T_{m}$ to

deF̃ne 그sing zone, $K$

axial velocity, $\mathrm{m} / \mathrm{s}$

radial pelociit, $\mathrm{m} / \mathrm{s}$

coorainaie in the axial direction

GREEK SYMBOLS

$\alpha \quad$ relaxation factor

$\delta\left(T-T_{m}\right)$ Dirac function

$\epsilon$ porosity

c contact angle of the liquid, deg

$\lambda$ length of mean free pakh, $m$

$\mu$ dynamic viscosity, $\mathrm{N}-6 / \mathrm{m}^{2}$

$v \quad$ kinematic viscosity, $\mathrm{m}^{2} / \mathrm{s}$

$\xi$ emissivity

$\rho$ density, $\mathrm{kg} / \mathrm{m}^{3}$

$\sigma \quad$ Steian-Bcitzmaan constant, $\mathrm{W} /\left(\mathrm{m}^{2}-\mathrm{K}^{4}\right)$

$\tau$ sheai stiess

$\omega$ surface tension. $5 / \mathrm{m}$

\section{SUBSCRIPTS}

il working substance in the liquid state in the wick

fs working substance in the soid state in the rick

$l$ liqud where there is liquid motion in the rick

b wick region where the working substance is in the liquid siaie

me wick region where the working substance is in the mushy state

- properties at the liquid-yapor interface

s wick structure material

se wick region where the working substance is in the solid state

$\nabla$ rapo: state

properties at the heat pipe wall

\section{INTRODUCTION}

The demand for an effective thermal management device for high temperature applications such as cooling the leading edges of reentry vehicies and hypersonic aircraft, and a space-based power station stimulates the study of the start-up of frozen liquid-metal beat pipes. Also, the start-up of frozen low temperature heat pipes is important in applications such as heat pipe heat exchangers, ccoling electronic equiprnent, and melting the snow and ice on roads and bridges.

Veal (196i) and Shlosinger (1968) performed the first expenmental tests to study the start-up performance of iow iemperature heat pipes with the water initially frozen. Deverall et al. (1970) also made a series of tests with water and liquid metal heat pipes. Successful start-up from the frozen state was possible but was highly dependent on the heat rejection rate at the condenser. Tolubinsky et al. (1978) investigated the start-up characteristics of sodium and potassium heat pipes. Camarda (1977) investigated the performance of a sodium heat pipe cooling a leading edge. Start-up and shut-down of a $4 \mathrm{~m}$ long lithium heat pipe was studied experimentally by Merrigan et al. $(1985,1986)$. Ivanovskii et al. (1982) presented the vapor temperature distribution along the length of a sodium heat pipe during the start-up period. Three flow regimes in the condenser are described based on the vapor temperature: free molecular llow, intermediate, and continuum vapor flow. Unfortunately, the existing experimental data for the start-up period are in general not represented in the archival literature and lack sufficient information for comparison with numerical simulations.

Colwell et al. (1987) and Jang (1988) developed a simple mathernatical model to predict the start-up behavior of a sodium heat pipe with a rectangular cross section from the frozen state. In the wall and wick structure, enerzy transport is described by the transiert, two-rimensional heat conduction equation, and the piase cinange of the working substance is taiken into accoint. In the vapor region, free molecular, choked and continum fows are considered and one-dimensional, compressible quasi-steady state laminar flow is assumed. The numerical results obtained by using the finite element method are in agreement with experimental results given by Camarda (1977).

The liquid metal heat pipe operates aot only at high temperatures but also the initial tern ferature may be ambient temperature. In this temperiture range, the working substance may be in the solid state as well as the liquid and vapor states. In the vapor space, free molecular low, continuum flow, sonic and supersonic flow may be encountered due to the extremeiy small density during the start-up of the heat pipe. These conditions may cause the failure of operation of the heat pipe and limit the performance of the heat pipe. Understanding the stari-up behavio and transient performance of the higi iemperatize heai pipe is therefore important and an efficient mathematical model is needed to predict this behavior.

The first part of this paper presents a complete mathematical model to describe the start-up behavior of the beat pipe from the fozen staie. This model is then simolined to obtain numetical results. To the authors: knowledge, the analysis presented bere is the only mod!l that incindes the efiect of the sransient vapo- tow in the analysis of the start-up of a heat pipe from the frozen state. After the mathematical models are tested secarately, the models are used for a parametric study of the siart-ap of frozen heat pipes.

\section{DESCRIPTION OF HEAT PIPE START-UP}

Previous experimental observations suggest the following sequence of evenis during heal pipe star:-up from the frozen state. Initially, the working substance is in the soiid state and the vapor density is extremely low, so that free molecular flow conditions prevail throughout the vapor space. The input heat flux over the evaporator increases the temperature and starts to meit the frozen substance in this region. Meanwhile, the heat transport from the heated zone to the adjacent pipe proceeds quite slowly via axial conduction through the heat pipe wall, working sabstance, and wick structure, while the heat transfer in the vapor is aimost negligible. Thus, a large temperature gradient exists between the evaporator and condenser.

When energy is continuously added to the evaporator, the frozen working substance in the evaporator is melted, so that evaporation can take place at the liquid-vapor interiace and the vapor density in this region is increased. The molecular mean free path in the heated region then becomes small compared to the diameter of the vapor passage and the continuum flow regime is established, while in the cooled zone the vapor is still in free molecular flow. In the continuum flow region, the vapor flows in to the condenser section due to the large pressure gradient. During this stage, energy is mainly transferred as latent heat owing to vaporization in the heated zone, and condensation in the cooled zone in the vapor space where continuum flow is estahlished. The temperature near the evaporator remains constant and the location of the temperature gradient moves toward the end of the condenser until continunm flow is establised in the entire vapor space. Cotter (1967) also described this frontal start-up mode when the vapor density is so $10 \mathrm{w}$ and non-condensable gas does not exist in the vapor space.

In heat pipes with metallic working substances, the vapor densities are very small during the start-up even in the continunm flow region. Thus, even for relatively low values of heat input, sonic vapor velocities can be reached. 
Also, the vapor flow in the heat pipe is qute simiar to the flow in a convergng-diverging nozzle due to the rapor acdition in the eraporator and the vapor removal in the cordenser (Drin and Reat, 1982) Thus, the heat transfer througa the vapor space may be limited by the choiked tlor condition, and supersome rapor flow and a snock front may occur in the continuum flow region in the condenser The maximum rate of heat transfer is limited by the sonuc limit so that a high heat input in the evaporator causes the vanous types of start-up fallure

The start-up process continues untll the frozen working suntance is completely melted and the continuum flow regime reaches the end of the heat pipe, at which time liquid returning to the evaporator is sufficient for normal transient operation Eventually, the heat pipe may reach a steady state condition The start-up process of the laquid metal heat pipe from a frozen state may be divided into several distinct penods for convenience of anaiysis based on tne staitus of the workng substance and the bebanor of the vapor low

1 In the tursi penod, no phase $c^{\text {s }}$ sage takes place in the enitre region but the temperature near the heated region increases The vapor llow is in the tee molecular condution

2 The rorking substance in the evaporator is in the ireud state, but evaporation does not occur at the houd-vacor in:erface

3 The Lquid and solid states of the forkang substanre exust simultaneously in the xick strictaie and vaporization of the working substance takes place at the lquu-vapor interiace In the vapor space, a region of convisutin fiow is establushed in the heated segion and a continuun fow front moves tow ard the cooled end of the heat pipe The rapor ilow mar be chohed at the beginning of tise connensei

4 The working substance is completely melted but free molecula: fow silil exsts in part of the vajor space

$j$ Cortinuum flow exasts over the entire hea! pive length in the vapor region but the heat pipe does not reacn tne steady state condition

5 The heat pipe then reaches the steady state cperation

For low temperature heat prpes, the experimental resuits of the successful start-ip from the frozen state are very rare Deverall ei al (1970) successfully started a water heat plpe from the frozer state $(208 \mathrm{~K})$ The wall temperature distnbution obtained is similar to that of high temperature heat pipes The vapor temperature was nor obtanned, but the vapor density is relatively high even around the melting temperature This means that the vapor velocity is very low so that choked flow and supersonic vapor velocities may not be encountered dunng start-up Unlike high temperature heat pipes, expenmental results show that the heat pipe becomes immediately active where the Ice is melted, but there still is a large temperature gradient in the axal direction The heat input at the evaporator should be low enough to return sufficient water into the evaporator for the successful start-up

\section{MATHEMATICAL FORMULATION}

Consideration is given to the heat pipe wall, the wick structure whth the workung substance inutially subcooled at a unform temperature, and the vapor region A schematic diagram of the physical model is shown in Fig 1

Heat Prpe Wall

In this region, the progress can be modeled by the heat conduction equation in a hollow cylinder The governing equation are expressed as follows

$$
\left(\rho c_{p}\right)_{w} \frac{\partial T_{w}}{\sigma \tau}=\frac{1}{\tau} \frac{\partial}{\sigma T}\left[K_{w} \frac{\partial T_{W}}{\partial \tau}\right]-\frac{\partial}{\partial x}\left[K_{w} \frac{\partial T_{w}}{\partial x}\right]
$$

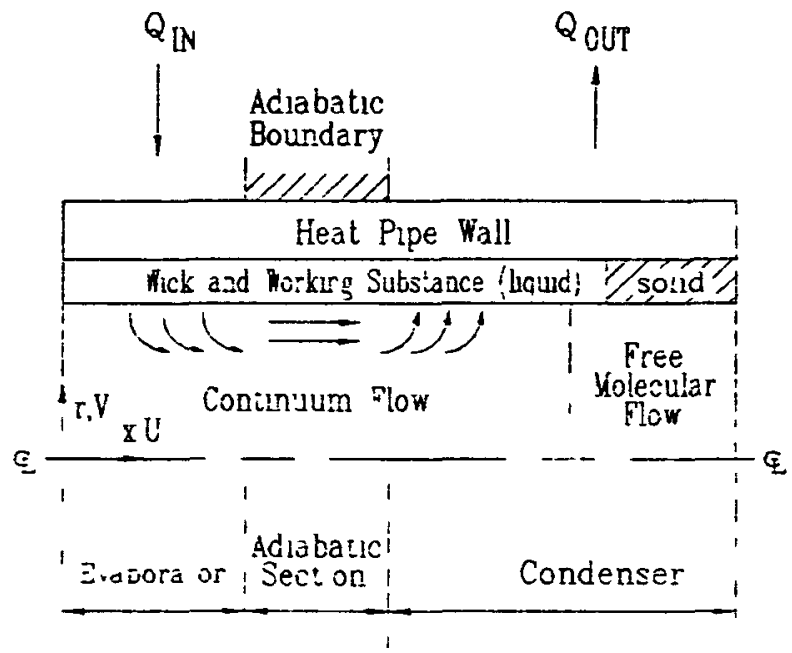

Fig 1 Schematic alagram and coordinate configuration of the heat pipe

Wick Struciute Reg:or

Intrally, the rorkrg sucstance is in the solid siate When heat is added to the evaporator ine frozer worlang substance in the heated regor is melted so ihat :he liqud and solud states o: the work.ng suostance exs: in the wick. Flud motion in the laqud iegron frat then occur due to vaporization and condensation of the forkung stbstance The hqud flow in the wick is considered to be unsteady two-dimensional incompressiole laminar flow with negligible body forces The flud and whck structure are assumed to be in local ecuinonum and the velocities in the axal and radial drrections are the local area-averaged velocities over a cross section of a finte element of the wick region instead of the pore velocity or actual velocity tlso the wick is assumed to be isotropic and homogeneous The governing equations for the wick region are formulated by using the princples of the conservation of mass, momentum, and energy The viscous dissipation terms in the energy equation are neglected

The continuty, momentum and energy equations are

$\frac{1}{\mathrm{r}} \frac{\partial}{\partial \mathrm{r}}(\mathrm{rV} \ell)+\frac{\partial \mathrm{U} \ell}{\partial \mathrm{x}}=0$

$\frac{1}{\epsilon} \frac{\partial \mathrm{V}_{\ell}}{\partial \mathrm{t}}+\frac{1}{\epsilon}\left[\mathrm{V} \frac{\partial \mathrm{V}_{\ell}}{\partial \mathrm{\partial \textrm {T }}}+\mathrm{U} \frac{\partial \mathrm{V} \ell}{\partial \mathrm{x}}\right]=-\frac{1}{\rho_{\ell}} \frac{\partial \mathrm{F} \ell}{\sigma \mathrm{T}}-\frac{\nu \ell \mathrm{V}_{\ell}}{\mathrm{k}}+$

$\frac{\nu_{l}}{\epsilon}\left[\frac{1}{r} \frac{\partial}{\partial r}\left[r \frac{\partial V_{\ell}}{\partial r}\right]-\frac{V_{\ell}}{r^{2}}+\frac{\partial^{2} V_{\ell}}{\partial x^{2}}\right]$

$\frac{1}{\epsilon} \frac{\partial \mathrm{U} \ell}{\partial \mathrm{t}}+\frac{1}{\epsilon}\left[\mathrm{v} \frac{\partial \mathrm{U} \ell}{\partial \delta \mathrm{r}}+\mathrm{U}_{\ell} \frac{\partial \mathrm{U} \ell}{\partial \mathrm{x}}\right]=-\frac{1}{\rho_{\ell}} \frac{\partial \mathrm{P} \ell}{\partial \mathrm{x}}-\frac{\nu_{\ell} \mathrm{U}_{\ell}}{\mathrm{k}}+$

$\frac{\nu l}{\epsilon}\left[\frac{1}{\tau} \frac{\partial}{\partial \tau}\left[r \frac{\partial \mathrm{U}}{\partial \mathrm{r}}\right]+\frac{\partial^{2} \mathrm{U} \eta}{\partial \mathrm{x}^{2}}\right]$ 


$$
\begin{aligned}
& \left(\rho c_{p}\right)_{i} \frac{\partial T_{i}}{\sigma t}+V_{l} \frac{\partial T_{i}}{\sigma r} \div U_{l} \frac{\partial T_{i}}{\sigma x}=\frac{1}{r} \frac{\partial}{\sigma r}\left[\mathrm{rK}_{\mathrm{i}} \frac{\partial \mathrm{T}_{\mathrm{i}}}{\partial \mathrm{r}}\right]+ \\
& \frac{\partial}{\partial x}\left[K_{i} \frac{\partial I_{i}}{\sigma x}\right] \\
& i=\left\{\begin{array}{l}
\text { se for solid tegion } \\
\text { me for mushy region } \\
\ell \text { e for I iquid region }
\end{array}\right.
\end{aligned}
$$

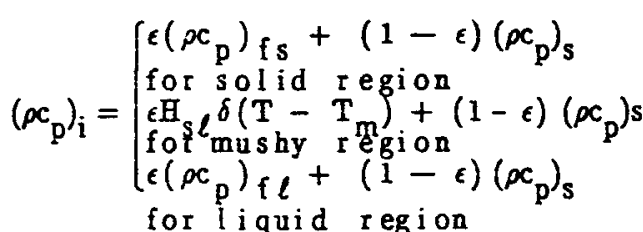

When the porosity approaches unity (no wick structure evisis), the permeability approaches inñnity. Therefore, equations (2-5) can be reduced to the Navier-Stokes equation for unsteady two-dimensional incompressible iarinar flow. For the steady state, equations (2-5) also appruach a special case given by Hong et al. (1985). The expressions for the porosity and the effective themal concuctivity of the scieen wicks are given by Chang (1987).

The governing equations (2-5), however, are not awars applicable. For example, during the second period the ilguid siate of the working substance exists in the wick but Evaooration of the working substance at the interface is negligible. Also, the liquid layer is so thin that the efiect of natural conrection in the liquid region is neglected. Thus, there is 20 fluid motion in the iquaid region so that oriy equation (j) without the second and third terms is aoplicable and equations (2-4) are useful after the second penod when there is liquid motion in the trick.

In addition to equations (2-5), coupling conditions at the liquid-solid inieriace are needed:

$$
\begin{aligned}
& \mathrm{T}_{s e}=\mathrm{T}_{\ell \mathrm{e}}=\mathrm{T}_{\mathrm{m}} \\
& \mathrm{K}_{\mathrm{se}} \frac{\partial \mathrm{T}_{\mathrm{se}}}{\partial \mathrm{n}}-\mathrm{K}_{\ell e} \frac{\partial \mathrm{T}_{\ell \mathrm{e}}}{\partial \mathrm{n}}=\epsilon \mathrm{H}_{s \ell} \frac{\mathrm{d} \overrightarrow{\mathrm{d}}}{\mathrm{t}}
\end{aligned}
$$

Vapor flow dynamics

Initially, the entire working substance is in the solid state so that the vapor space may be nearly evacuated. As the temperature at the interface increases, the vapor density also increases. Continuum flow in the vapor space is considered to be established when the mean free path, $\lambda$, is substantially less than the mininum dimensions of the vapor flow passage (Holman, 1981), e.g.

$$
K_{n} \equiv \frac{\lambda}{D} \leq 0.01
$$

The tiansition temperature, $\mathrm{T}^{*}$, of the vapor corresponding to the given dimension of the vapor space is expressed by using the kinetic theory of gases as follows (Jang, 1988):

$$
\mathrm{T}^{*} \geq \frac{\pi}{2 \times 10^{-4}} \frac{\mathrm{M}}{\mathrm{R}_{\mathrm{u}}}\left[\frac{\mu \mathrm{v}}{\rho_{\mathrm{v}} \mathrm{D}}\right]^{2}
$$

When the vapor temperature is greater than that calculated by equation (10), continuum flow is assumed to be established in the vapor space.

When continuum flow is established in the vapor space during the start-up from the frozen state, complex flow phenomena are encountered in the continuum flow region due to the extremely small density of the rapor. The vapor pressure is low and the temperature and pressure gradients are large in the axial direction, so the vapor velocity may reach the sonic velocity, and supersonic vapor flow and a shock front may occur in the condenser. Thus, the effects of compressibility, friction at the liquid- vapor interface and dissipation in the vapor should be considered in the mathematical model. The vapor flow may be considered to be axisynmetric, compressible, unsteady laminar flow and the governing equations for this flow are formulated with negligible body forces and heat sources as follows. In cylindrical coordinates, the continuity, momentum and energy equations are:

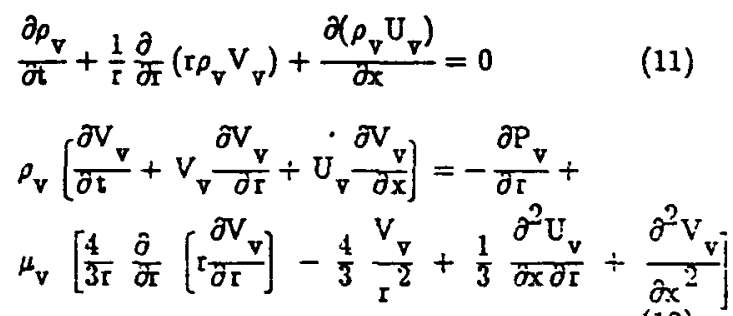

$$
\begin{aligned}
& \rho_{\mathrm{v}}\left[\frac{\partial \mathrm{U}_{\mathrm{v}}}{\partial \mathrm{t}}+\mathrm{U}_{\mathrm{v}} \frac{\partial \mathrm{V}_{\mathrm{v}}}{\partial \mathrm{r}}+\mathrm{U}_{\mathrm{v}} \frac{\partial \mathrm{U} \mathrm{v}}{\partial \mathrm{x}}\right]=-\frac{\partial \mathrm{P}_{\mathrm{v}}}{\partial \mathrm{x}}+ \\
& \mu_{\mathrm{v}}\left\{\frac{1}{\mathrm{r}} \frac{\partial}{\partial \mathrm{T}}\left[\mathrm{r}\left[\frac{\partial \mathrm{V}_{\mathrm{v}}}{\partial \mathrm{x}}+\frac{\partial \mathrm{U}_{\mathrm{v}}}{\partial \mathrm{r}}\right]\right]-\frac{2}{3} \frac{\partial}{\partial \mathrm{x}}\left[\frac{1}{\mathrm{r}} \frac{\partial}{\partial \mathrm{T}}\left(\mathrm{r} \mathrm{V}_{\mathrm{v}}\right)\right]\right. \\
& \left.+\frac{1}{3} \frac{\partial}{\partial \mathrm{x}} \quad\left[\frac{\partial \mathrm{U}_{\mathrm{v}}}{\partial \mathrm{x}}\right)\right\}
\end{aligned}
$$

$$
\begin{aligned}
& \rho_{\mathrm{v}} \mathrm{C}_{\mathrm{pv}}\left(\frac{\partial \mathrm{T}}{\partial \mathrm{t}}+\mathrm{v}_{\mathrm{v}} \frac{\partial \mathrm{T} \mathrm{v}}{\partial \mathrm{T}}+\mathrm{U}_{\mathrm{v}} \frac{\partial \mathrm{T} \mathrm{v}}{\partial \mathrm{X}}\right]= \\
& \frac{1}{\mathrm{r}} \frac{\partial}{\partial \mathrm{r}}\left[\mathrm{rK}_{\mathrm{v}} \frac{\partial \mathrm{T}_{\mathrm{v}}}{\partial \mathrm{I} j}+\frac{\partial}{\partial \mathrm{x}}\left[\mathrm{K}_{\mathrm{v}} \frac{\partial \mathrm{T} \mathrm{v}}{\sigma \mathrm{x}}\right]+\frac{\partial \mathrm{P}}{\partial \mathrm{v}}+\mathrm{V}_{\mathrm{v}} \frac{\partial \mathrm{P}}{\partial \mathrm{v}}+\right. \\
& \mathrm{U}_{\mathbf{v}} \frac{\partial \mathrm{P}}{\sigma \mathrm{v}}+\mu_{\mathbf{v}} \phi
\end{aligned}
$$

Where:

$$
\begin{aligned}
& \dot{\phi}=2\left[\left[\frac{\partial \mathrm{V} v}{\partial \mathrm{r}}\right]^{2}+\left[\frac{\mathrm{V} v}{\mathrm{r}}\right]^{2}+\left[\frac{\partial \mathrm{U} \mathrm{v}}{\partial \mathrm{x}}\right]^{2}+\frac{1}{2}\left[\frac{\partial \mathrm{V} \mathrm{v}}{\partial \mathrm{r}}+\right.\right. \\
& \left.\left.\frac{\partial \mathrm{U}_{\mathrm{v}}}{\partial \mathrm{r}}\right]^{2}-\frac{1}{3}(\nabla \cdot \mathrm{V})^{2}\right] \nabla \cdot \mathrm{V}=\frac{1}{i} \frac{\partial}{\partial \mathrm{T}}\left(\mathrm{r} \mathrm{V}_{\mathrm{v}}\right)+\frac{\partial \mathrm{U}_{\mathrm{v}}}{\partial \mathrm{x}}
\end{aligned}
$$

The numericai and analytical solutions of the above equations onder steady state conditions for annulaz and conventional heat pipes were given by Faghri (1986) and Faghri and Parvani (1988). Transient results are needed for the start-up from the frozen condition.

\section{Initial and Boundary Conditions}

Initially, a uniform temperature for the wall, wick, and vapor regions is assumed which is less than the melting temperature of the working substance. So, the entire worling substance in the wick is in the solid state. The heat llux, convection and radiation boundary conditions are applicable at the outer surface of the evaporator and condenser of the heat pipe. Both ends of the heat pipe are assumed to be insulated. When the liquid motion exists in the wick structure, the no-slip condition is used for the velocities at the interface between the heat pipe wall and the wick structure.

The boundary conditions at the liquid-vapor interface change during the start-up process. In the first and second periods, free molecular flow is prevalent in the 
vapor space so that heat transier tnrough the vapor space is negligiole Therefore, the adiabatic condition is employed at the squd-rapor interface When conturnum fiow is established in the vapor soace, vaponzation and condensation of the working suosiance at the interface is considered by using interace energy and mass balances The vapor temperature at the interface is assumed to be the saturation temperature corresponding to the vapor pressure at the interiace The Clausius-Clapeyron relationshp is used to ootan the saturation temperature The continuty of the axal velocity and shear stress is also used The pressure difference at the liquid-vapor interface induced from the action of the surface tension is given by using the Laplace and Young equation This condition couples the liqud and vapor momentum equations at the liquid-vapor interface

While part of the vapor space is in the continuum flow reg:me, free molecular flow also exasts in the rest of the vapor space Even though the heat transfer through the free molecular llow region may be negligiole, the boundary conditions at the border of the two regions are needed to solve the goverming equations for the contizuum flow region Since a large temperature gradient exasts in the continuum low region in the condenser dunng stat-up, most of the vapor may be condersed at the interiace Thus the vapor Denetration in the free rolecular Jow iegon may be minimal or penerraion ray occur in ibe 1 mmediate vicisliy of the nteriace cetween the cont num low regon and the iree motecular flow te jun tho, the temperature in the regior of free mulect'a- fow remains inchanged except in ine vicinity of ine cortinuum flow region ale to the near - acuum. Tnerefore, an imagnnary plane, which is adiabatic and normal to the arcal direction, is assumed to divide :ie :wo vasor flow regions at the point of the transition temperature The anding plane moves towarts the cooled end of the heat pipe as the location of the transition temperasure at the Laud-vapor interiace moves

The azosymmet $r c$ condition along the centerune of the heat pipe is used in continuam ficw region Tre no-sip condition and the adiabatic condition at Doth ends of the heat pipe is aiso usec for the velocities and temperature The pressure and densivy at both ends of the heat pipe are unknown but the vapor velocis near the ends of the heat Dive is so low that the anal pressure and densty fradients are assumed to be zero fll of the boundary conditions for a mathematical model of the heat prpe start-up from the frozen state is summanzed in Table 1

\section{SIMPLIFICATION OF THE MODEL}

The matherratical model, equations $(1-14)$, for tne start-up behavior of the liqud metal heat pipe described in the previous sectson includes most of the physical phenomena which may occar in the heat pipe Therefore, this model is very complex to solve numencally The effect of some phusical phenomena may be negligible, so a simplified model is denved to predict the performance of the heat pipe dunng the start-up penod For this purpose, assumptions are made based on the cnaractenstics of the heat pipe and previous studies

The density of the liquid state of the workng substance is much greater than that of the vapor state, so the velocity of the workug substance in the wick structure is small The thermal conductivity of the liquid metal is large and the thickness of the wick region is very thin It is then assumed that the effect of the liqud flow in the wick structure is negligible and the wick structure is saturated by the working substance Thus, the heat transport through the wnck structure and workng substance is by conduction only but the phase change of the working substance is considered Under these assumptions, the same governing equation is also applicable to the heat pipe wall and the mick structure by using the proper properties for each region The governing equawon is given as follows

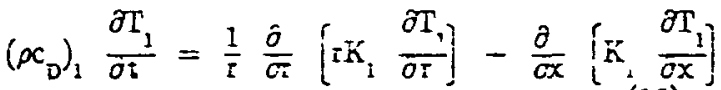

$$
\begin{aligned}
& t=\left[\begin{array}{l}
w \text { for wall region } \\
\text { se for solid region in the wick } \\
\text { me for mushy region in the wick } \\
\text { le for liquid region in the wick }
\end{array}\right.
\end{aligned}
$$

The expression of $\left(\rho c_{p}\right)_{1}$ for the whck structure region is given by equation (6) The thermal conductivity, $K_{1}$, can be the thermal conductivity of the wall matenal for the wall region When the effective thermal conductinty for the wick region is calcuaied by using the expression guen ty Chang (1987), the thermal conductinty for the workung substance is substituted by the solud conducrurty, hqud conduct.vity, or the average value oi the solva anc Lqua corductinty of the woth is subsiance ccriespuading to the soid, houd, or musny region, respecinely

The vapor tow is also simplifed furtner from the two-inarsional zodel to a one-dimonsional godel since a previcus study (jarg ez al, 198g) shows that the one-dimens'onal :iansient compiessible model described the vapor tow djzamics as well as the tro-dirersional mooel for simulated heat pide vapor low The transient compressibie one-dimensional continuty, momentum and energy equation are written as follows

$$
\begin{aligned}
& \frac{\partial}{\partial t}\left(\rho_{v}\right)+\frac{\delta}{\partial x}\left(\rho U_{v}\right)=\frac{A_{0} \rho_{0}(x)}{\bar{\nu}} \\
& \frac{\partial}{\sigma}\left(\rho_{\mathrm{v}} \mathrm{U}_{\mathrm{v}}\right)+\frac{\partial}{\partial x}\left(\rho_{\mathrm{v}} \mathrm{U}_{\mathrm{v}} \mathrm{U}_{\mathrm{v}}\right)+\frac{\partial}{\partial x}\left[\mathrm{P}_{\nabla}-\frac{4}{3} \mu_{\mathrm{v}} \frac{\partial \mathrm{U}}{\partial \mathrm{x}}\right] \\
& =-\frac{2 \rho_{\mathrm{v}} \mathrm{V}_{\mathrm{v}}^{2} \mathrm{f}}{\mathrm{D}} \\
& \frac{\partial \mathrm{E}_{\mathrm{v}}}{\partial \tau}+\frac{\partial}{\partial \tau}\left[\mathrm{U}_{\mathrm{v}}\left(\mathrm{E}_{\mathrm{v}}+\mathrm{P}_{\mathrm{v}}\right)-\frac{\frac{1}{3}}{3} \mu_{\mathrm{v}} \frac{\partial \mathrm{U}_{\mathrm{v}}}{\partial \mathrm{x}} \mathrm{U}_{\mathrm{v}}-\mathrm{K}_{\mathrm{v}} \frac{\partial \mathrm{T} \mathrm{v}}{\partial \mathrm{x}}\right) \\
& =\frac{4 \rho_{0} V_{0}(x)}{D}\left[\tilde{s}_{0}(x)+\frac{V_{0}^{2}(x)}{2}\right]+\frac{2 \rho_{v} U^{2} \tilde{L}}{D} U_{v}
\end{aligned}
$$

Since the governing equations are simplified, the coriesponding boundary conditions are aiso modified to match the governing equations

\section{NOMERICAL PROCEDURES}

The governing equations are separately solved for each region When the coupling is implemented at the interface, iterations are needed To reduce the amount of computer time, non-iterative schemes are employed for each region The well-known alternating direction implicst (ADI) method is used for the heat pipe wall and wick, and the phase change of the working substance dunng start-up is modeled by using the equvalent heat capacity method (Hsiao, 1985) This method approxamates the rapid change of the heat capacity over the phase change temperature range, which is an artificially defined finte temperature range, $\Delta T$, instead of using the Dirac function In the numerical calculation, this property is evaluated based on the nodal temperatures The implicit Beam-Warming method is used for the vapor flow dynamics The detaled numerical method for the vapor flow in the heat pipe is described by Jang et al (1989) 
After contisum flow exisis in the rapor space, ecuation (15) sinould be corpled friti equations (16-18) br wing ine same bouncary conditions at the interiace. The cripiing of the governing equations for the vapor region to those for the wail and wick regions tould be achieved by nsing the heat fiux and the saturation temparaiure at the interface. However, the beat flux at this interface and the saturation temperature are initially unknown, so that these boundary conditions should be assumed and iterations are needed for each time step until the coupling conditions are satisfied along the interface. The numerical procedure used for coupling is as follows:

1. It is assumed that the liquid-vapor interface temperature is the initial temperature for the first time step.

2. Solve for the temperatures in the wall and wick regions.

3. Calcuiate the heat luxes, $q$, at each node of the liquid-vapor interiace by usiag the temperatures $\left(T_{j-1}\right.$ and $\left.T_{j}\right)$ in the wick region.

$q=k \frac{\left(T_{j-1}-T_{j}\right)}{I_{I}}$

4. These heat fiuxes are used as the boundary conditions at the interiace to solve ior ternpezatures in ine wall and wick regions.

5. Use the same heat fluxes to solve the vapor temperature and pressure for the same period at the wall and rick regions. Obtain the saturation temperature, $T_{S^{2}}$ by using the Clausius-Clapegron relationship.

6. Calculate the new heat fluxes, $q^{\prime}$, at the interiace by using the saturation temperature, $T_{s}$, in the wick.

$q^{\prime}=K_{l e} \frac{\left(T_{j-1}-T_{s}\right)}{1.5 \Delta r}$

7. Compare the new heat fiuxes, $q^{\prime}$, with the old heat Iuxes, $q$, at each node of the inieriace.

8. If the difference between the new heat flux and old heat flux is within an acceptabie range, repeat steps 4 to 7 for the next time step.

9. If the difference between the new heat fux and the old heat fox is not within the acceptable range, assume new guessed heat fluxes, q", by using the relaxation method and repeat steps 4 to 7 until the comparison of the results is acceptable.

$q^{\prime \prime}=q+\alpha\left(q^{\prime}-q\right)$

10. Repeat steps 4 to 9 until the temperatures reach the steady state.

When the coupling of the governing equations is attempted, some physical characteristics of the two regions are considered. Since the density of the vapor is much smaller than that of the liquid, the volumetric specific heat $\rho c_{p}\left(=8.8 \mathrm{~J} / \mathrm{m}^{3} \mathrm{~K}\right)$ for the vapor is much smaller than that $\left(=1040.1 \mathrm{KJ} / \mathrm{m}^{3} \mathrm{~K}\right)$ for the liquid. Therefore, a difference between the transient response times of the vapor region, and the wall and wick regions exists. The time step for the vapor space should then be much smaller than that for the wall and wick regions. The governing equations for the wall and wick regions are solved for one time step by using the heat flux assumed at the interface, and then the gcverning equations for the vapor space are solved by using the same heat Gux at the interface and smaller time steps for the same period as the wall and wick regions.

\section{RESULTS AND DISCUSSION}

The governing equations for the wall and wick regions and the vapor how are separately soived, and then are coupled at the liquid-vapor interiace. Therefore, the numerical methods and algorithms can be separately tested and compared to the available data. Since the working substance changes phase from the solid state to the liquid state during the start-up period from the frozen state, this effect should be incorporated into the numerical model. The solidification of.sodium in a square region is chosen to verify the numerical model and algorithm for governing equation (15). The results are in agreernent with available data (Rathjen and Jij, 1971 ). The transient one-dimensional model for the vapor flow dynamics in the heat pipe has already been verified by Jang et al. (1989). The combined model is used to predict the performance of the liquid-metal heat pipe.

\section{Simulation of the heat pipe start-up ir the iritial stoges}

Previous experimental results (Dererail et al., 1970) show that successiul sta:t-up of the fiozen heat pipe greaily depends on the boundary condition at the outer surface of the evaporator and conderser. For successful start-up from the frozen state, the heat input and otiput should melt the working substance in the condenser and allow sufficient liquid to zeturn to the evaporaior. All of the previous experimental results show the wall suriace temperatures, so that even for successful start-up the status of the working substance with time is toknown. Thus, the governing equations which described the start-up behavior of a crindrical heat pipe daring the first and second periods are solsed numerically to examine the eifiect of the boundary conditions and to recommend the optimum boundary condition:

The physical model has evaporator, adiabatic, and condenser seciion lengtins of $0.2,0.1$ and $0.2 \mathrm{~m}$, respectively. The racius of the vapor stace and the inner and outer radii of the heat pipe wall are $0.00585,0.008$, and $0.01 \mathrm{~m}$, respectively. The material for the heat pipe wall and wick structure is stainless steel (AISI 316). Sodium initially in the solid state at the ambient temperature is used as the working substance. The melting temperature of sodium is $371 \mathrm{~K}$ and the transition temperature of $680 \mathrm{~K}$ is. obtained by using equation (10) for the radius of the vapor space $(0.00685 \mathrm{~m})$ by iteration. Three different boundary condition cases are chosen for the outer surface of the heat pipe. A uniform input heat fiux of $50 \mathrm{KW} / \mathrm{m}^{2}$ and radiative heat output are used on the evaporator for all three cases. An emissivity of 0.9 and a radiation reference temperature of $293 \mathrm{~K}$ are empioved. The boundary conditions at the condenser and adiabatic sections are changed while that at the evaporator remains the same for all three cases. The liquid-vapor interface is assumed to be adiabatic due to the free molecular flow in the vapor space during initial two periods.

For case 1 , only radiation is used in the condenser to reject heat. Figure 2 shows the temperature distributions at the heat pipe outer wall surface and the liquid-papor interface. As heat is added in the evaporator, the temperature in the evaporator increases and at 20 seconds the working substance in the evaporator is in the liquid state. However, the temperature in the condenser is not changed from the initial temperature and in the adiabatic section the temperature in the region adjacent to the evaporator increases due to axial conduction. Additional heat input in the evaporator increases the temperature above the transition temperature in the evaporator, but the temperature in the condenser is still not changed so that a large temperature gradient exists. In the adiabatic section, part of the working substance (sodium) is in the liquid 
Staie. When the heat inpui is continued at the evaporator, raporization occurs at the interface in the eraporasor. However, the working snostance in most of the adiabatic section and conderser is in the solid state. Thereiore, the hea: inpui in the evaporator should be smail to prevent $\dot{c} r y-2 u t$ of the wick structure while the working substance in the solid state is melted. Even though successtul start-up may be possible for this case, the start-up progresses very slowly.

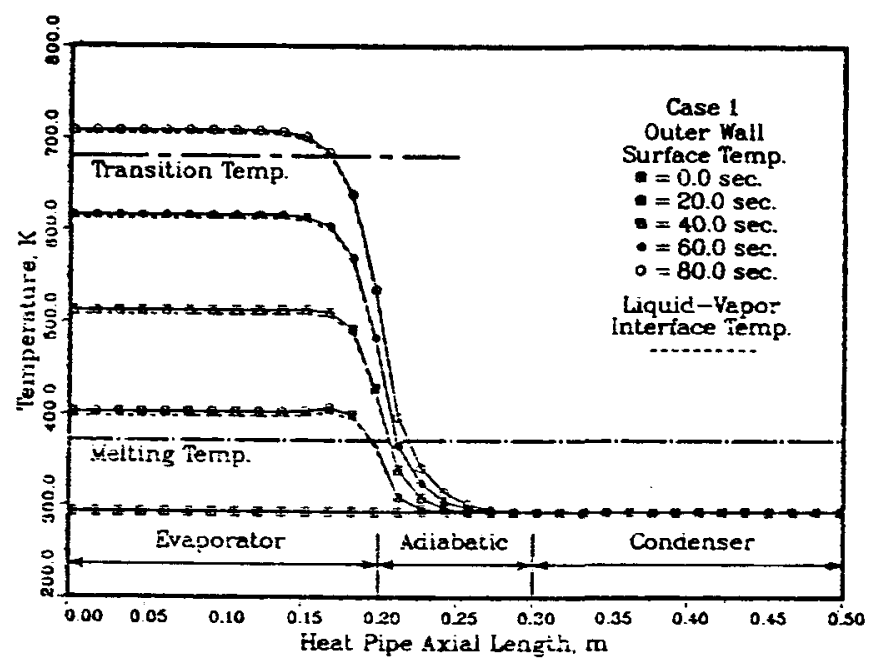

Fig. 2 Temperature distribution at the oxter wall sufface and liquid-vapor interiace of the heat pipe wall with tirie for case 1 .

For case $2,10 \mathrm{~kW} / \mathrm{m}^{2}$ is added in the condenser in addition to the radiative boundary condition to assist in the start-up of the frozen heat pipe. Figure 3 shows the temperature distributions at the outer wail suriace and liquid-vañor interface. Since a small amount of heat is added in the condenser, the temperature in the condenser is raised above the melting temperature. However the temperature in the adiabatic section is still below the

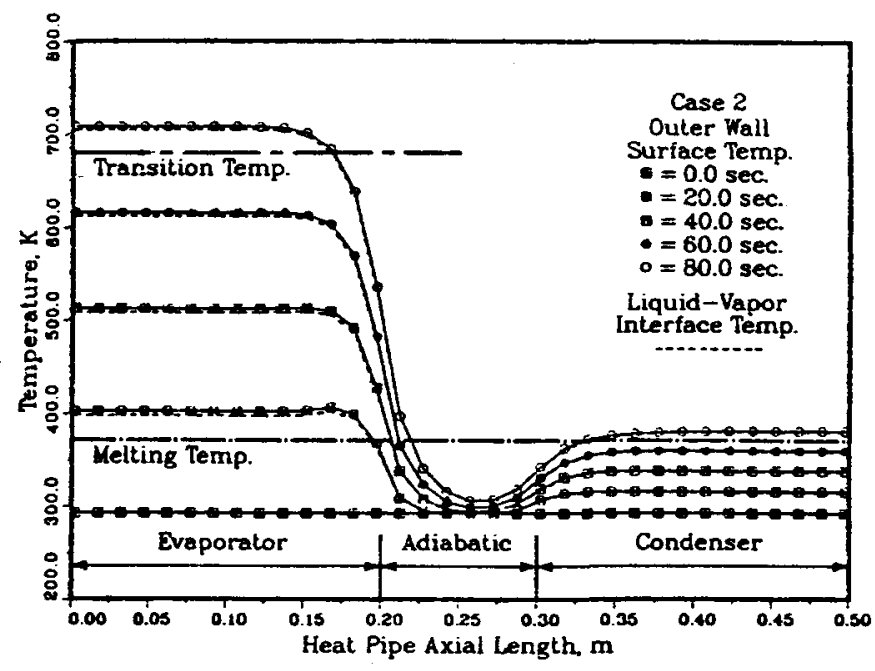

Fig. 3 Temperature distribution at the outer wall surface and liquid-vapor interface of the heat pipe wall with time for case 2. melting temperature. Thus, liquid in the condenser cannot flow to evaporator woil the working substance in the adiabatic section liquenes. The temperature in the adiaiatic section increases relatively faster than that for case 1 due to heat iransier at both ends of the adiabatic section. The start-up period may be shorter than that for case 1.

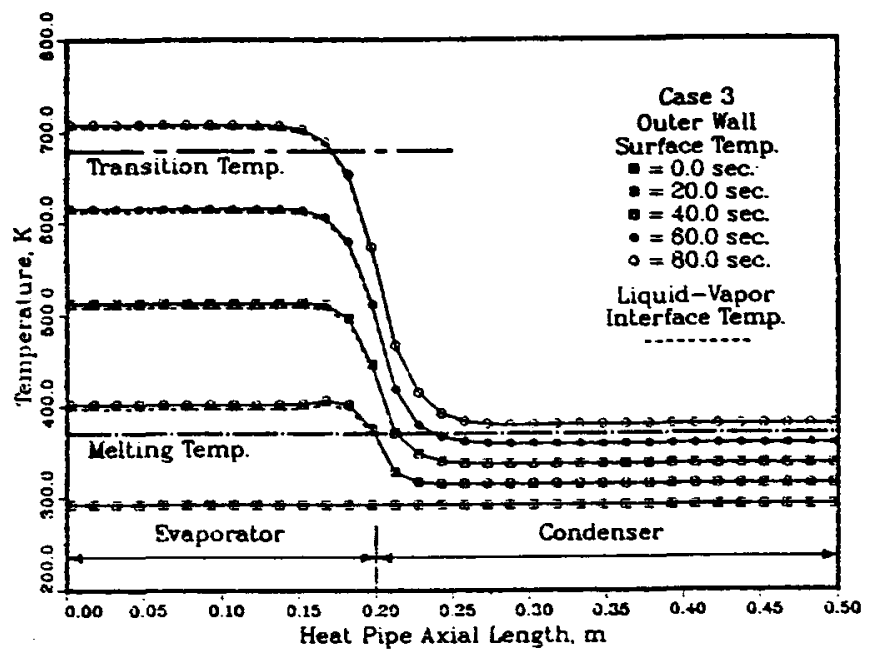

Fig. 4 Temperature distribution at the outer wail surface and liquid-rapor interface of the heat pipe wall with time for case 3 .

Finally, the adiabatic section is used as part of the condenser and $10 \mathrm{~kW} / \mathrm{m}^{2}$ of heat is input in the condenser secion. Figure 4 shows the temperature distributions at the heat pipe surface and the liquid-vapor interface and Fig. 5 shows the surface temperature at different times. Even though a large iemperature gradient still exists along the axial direction, the working substance is completely.melted in the entire heat pipe in 80 seconds. When vaporization occurs in the evaporator, the working substance can flow from the condenser to the evaporator to prevent dry-out of the wick structure in the evaporator. Thus, a relatively large amount heat can be added at the evaporator without dry-out so that the start-up period is expected to be much less than those of cases 1 and 2 .

\section{Transient Heat Pipe Operation}

To simulate the coupling of the governing equation for the wall and wick to that for the vapor flow, the same physical heat pipe model is used except that the adiabatic section is eliminated. Sodium is employed as the working substance. In order to concentrate on the coupling problem, it is assumed that continuum flow is established in the entire vapor space and the working substance is in the liquid state. To yield these conditions, a uniform initial temperature of $800 \mathrm{~K}$, which is greater than the transition temperature $(680 \mathrm{~K})$, is used for the wall, wick, and vapor regions. The external surfaces of the heat pipe wall at the evaporator and condenser are exposed to a uniform heat flux of $50000 \mathrm{~W} / \mathrm{m}^{2}$ and a convective boundary condition, respectively. A reference temperature of $300 \mathrm{~K}$ and a heat transfer coefficient of $100 \mathrm{~W} / \mathrm{m}^{2} \mathrm{~K}$ are used for the convective boundary condition at the condenser section. The time step for the vapor space should be much smaller than that for the wall and wick regions, so a time step of 0.1 


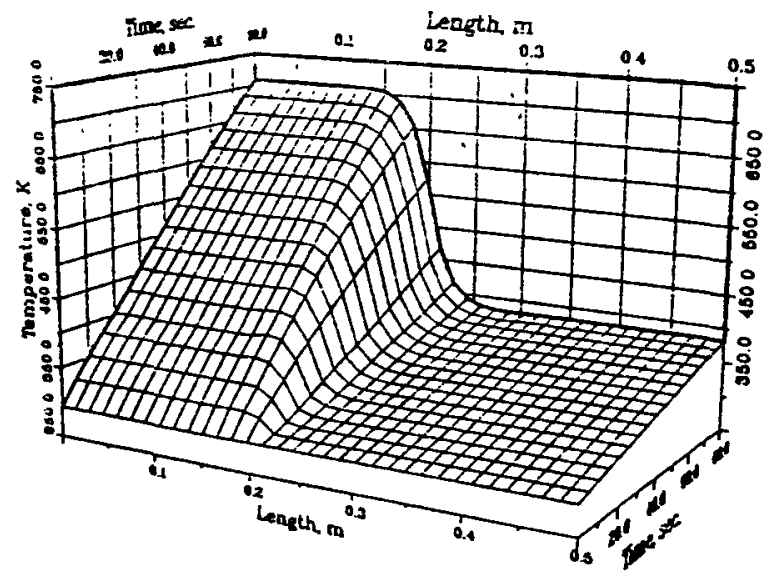

Fig. 0 Temperature distribution at the outer wall surface of the beat pipe wall with different times for case 3 .

second is employed for the wall and wick regions and time sies of $0.1 \times 10^{-3}$ second is used for the vapor flow. Twenty nodes in ine radial direction and 160 nodes in the axial Erection are used at the wall and wick regions. Also, 160 nodes are employed along the vapor space. A relaxation factor of $\alpha=0.00003$ is used to obtain the new guessed hear Dlux.

Figure 6 stows the temperature distributions at the onte: wall suriace, lioud-vador interface, and the saturation temperature for a tirie of 0.3 second. The temperature distribution at the outer wall surface is uniform whitin each section, and near ine border betweer the evaporaior and condense tine suriace temperature abruptly changes corresponding to the boundary conditions at the suriace. The interiace temperature matches well with the

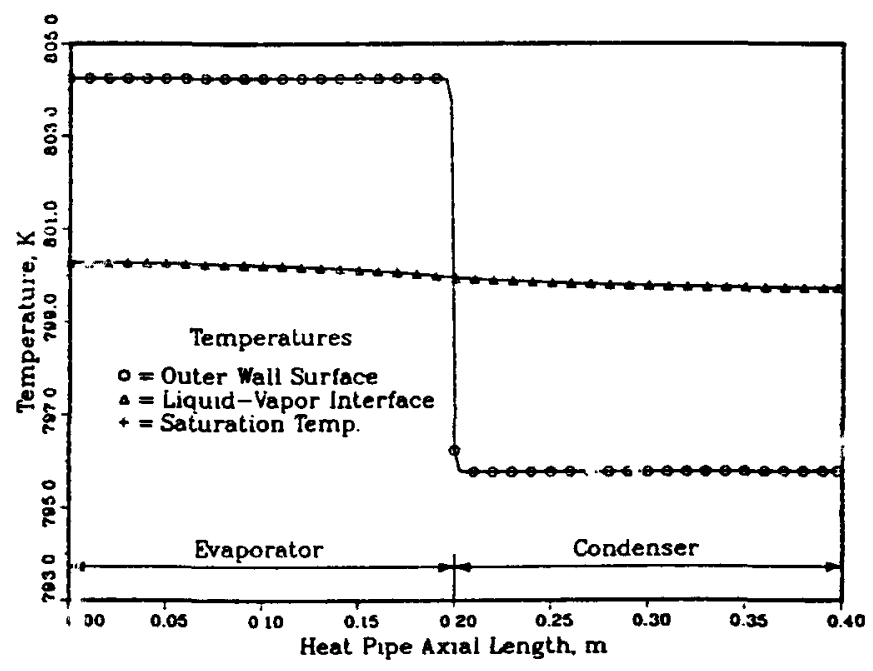

Fig. 6 Temperature distributions at the outer wall surface and liquid-vapor interface, and saturation temperature for time of 0.3 second. saturation temperature which is evaluated by using the Clausius-Clapeyron relationship with the vapo- pressure. The saturation temperature decreases gradually. Figcie 7 shows the heat flux distribution at the interface. The new heat tux calculated is converged to the old heas fiux. The maximum difference between the two heat iluxes is about $10 \%$. Even though the heat flux at the surface is reiatively uniform, the heai flux at the interface is not uniform. Also, the heat flux at the interface is much less than that at the surface. This implies that most of the energy is used to raise the wail and wick temperature at this moment. Figure 8 shows the vapor temperature, pressure, relocity, and density distributions. The variation of the vapor temperature,

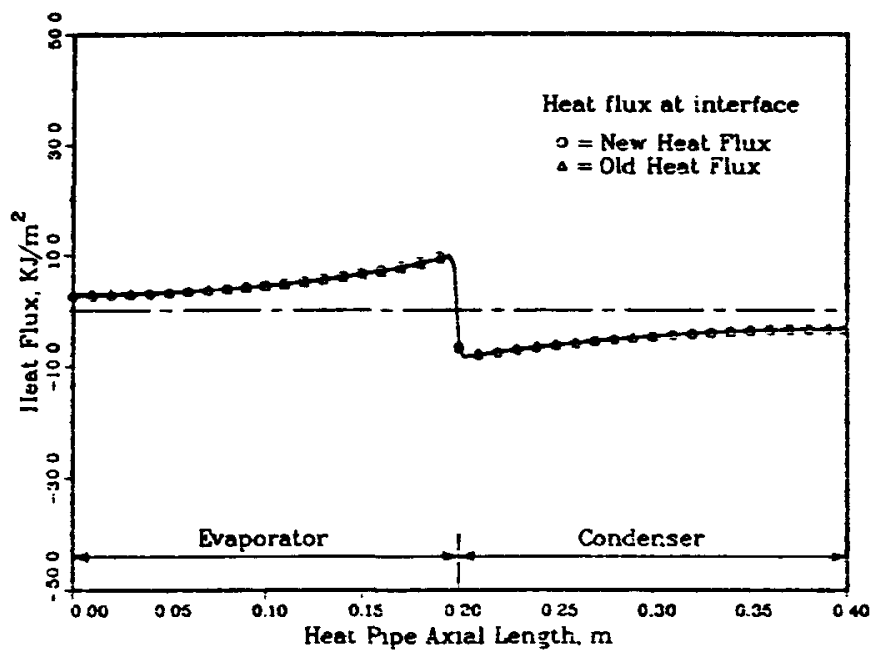

Fig. 7 Comparison of new heat nux with oid heai flux at the interiace for time of 0.3 second during transient continnum flow.

pressure, and density is small. Also, a Mach number of $\mathbf{M}=$ 0.027 is obtained at the exit of the evaporator.

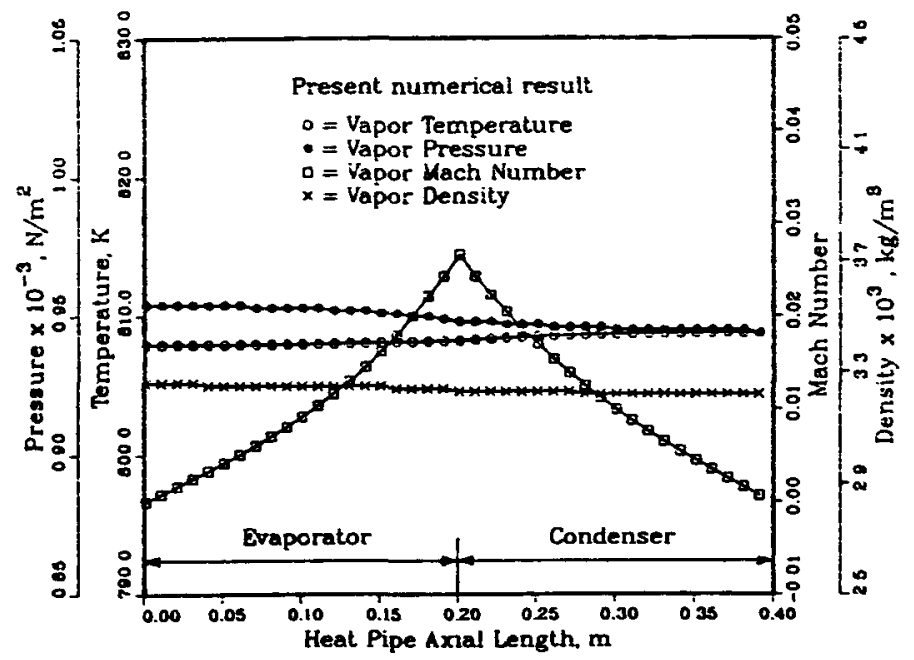

Fig. 8 Axial variations of temperature, pressure, density and velocity for time of 0.3 second during transient continuum flow.

\section{CONCLUSIONS}

The start-up process of the frozen heat pipe is 
described based on the experimental results. A complete mathematical model is developed to predict the star-ap behavior of the heat pipe rrom the frozen condition. The simplified model is used to obtain the numerical results. The numerical results during the first and-second periods show that the heat flux distributions 'for the evaporator and condenser should be chosen to melt the working substance in the condenser prior to vaporization occurring in the evaporator. A small amount of heat input at the condenser helps start-up and a high heat rejection at the condenser during the start $\rightarrow$ up should be avoided. The coupling of the two-dimensional transient model for the wall and wick to the one-dimensional transient model for the rapor flow is achieved when continuum flow exists in the vapor space. During the transient operation, the heat flux distribution at the interface is quite different from that at the surface. Efforts to improve the present model will continue.

\section{ACKNOWLEDGEMENT}

Funding for this work was provided by a joint efior of the NASA Lexis Research Center and the Thermal Energy Group of the Aero Propulsion and Power Laboratory of the U.S. Air Force under contract F33ô15-88-C-2820.

\section{REFERENCES}

Carrarda, C.J., 1977, "Analysis and Radiant Heating Tests of a Heat-Pipe- Cooied Leacing Edge," NASA T.Y $-84 \delta 6$.

Chang, W.S., 1987, "EFective Thermal Conductivity of Wire Screens," Furdamentals of Conduction and Recent Developments in Cantact Resistance, HTD-Vol. 69, pp. 54-i5.

Colwel!, G.T.. Jang, J.H., and Camarda, C.J., 1987, "Mcdeing of Startup from the Frozen State," Proc. 6th Int. Hear Pije Conf, France. Vol. 1, pp. 16j-170.

Cútier, T.P., 1967, "Beat Pipe Startup Dynamics," Proc. IEEE Thermionic Conversion Soecialist Conf., Palo Alto Caiif, pp. 344-348.

Deverall, J.E., Kemme, J.E., and Florschuetz, L.W., 1970, "Sonic Limitations and Stariup Problems of Heat Pipes," LA -4518.

Dunn, P.D., and Reay, D.A., 1982, Heat Pipes, 3rd Ed., Pergamon Press, Oxford.

Faghri, A., 1986, "Vapor Fiow Analysis in a Doubie-Walled Concentric Heat Pipe," Numerical Heat Transier, Vol. 10, No. 6, pp. 583-595.

Fagnir, A., and Parvani, S., 1988, "Numerical Analysis of Lamina: Flow in a Double-Wailed Heat Pipe," J. Thermophrsics and Heat Transier, Vol. 2, No. 3, pp. $165-171$.

Holman, J.P., 1981, Heat Transfer, 5th Ed., McGraw-Bill Book Co., New York.

Hong, J.T., Tien, C.L., and Kaviany, M., 1985 , "Non-Darcian Effects on Vertical-Plate Natural Convection in Porous Media with High Porosities," Int. J. Heat Mass Transfer, Vol. 28, pp. 2149-2157.

Isiao, J.S., 1985, "An Efficient Algorithm for Finite-Difference Analysis of Heat Transfer with Melting and Solidification," Nnmerical Heat Transfer, Vol. 8, pp. $653-666$.

Ivanovskii, M.N., Sorokin, V.P., and Yagodkin, I.V., 1982, The Physical Principles of Heat Pipes, Clarendon Press, Oxford.

Jang, J.H., 1988, "An Analysis of Startup from the Frozen State and Transient Periormance of Heat Pipes," Ph.D. Dissertation, Georgia Institute of Technology.

Jang, J.H., Faghri, A., and Chang, W.S., 1989, "Analysis of the Transient Compressible Vapor Flow in Heat Pipes," Proc. of 26th National Heat Transfer Conf, Philadephia, Pennsylvania.
Merigat, M1.A., Kediy, E.S., and Sena, J.T., 1985, "Trarsien: Eleat Pipe Investigations ior Space Power Sysiecs," IA-Uih-Sj-334I.

Merrigaa, Mi.4., Kejdy, E.S., anc Sena, J.T., 1950, "Transient Performance I livestigazion of a Space Power System Heat Pipe," AIAA Paper No. AIAA-86-1273.

Neal, L.G., 1967, "An Analysis and Experimental Study of Heat Pipes," TRW System Rept. No. 99900-6114-R000.

Rathjen, K.A., and Jï̈, L.M., 1971, "Heat Conduction with Melting or Freezing in a Corner," J. Heat Transfer, Vol. 93, pp. 101-109.

Shlosinger, A.P., 1968, "Bleat Pipe Devices for Space Suit Temperature Control," TRW System Rept. No. 06462-6005-RO-00.

Tolubinsky, V.I.; Shevchuk, E.N., and Stambrorsky, V.D., 1978, "Study of Liquid-Metal Heat Pipes Characteristics at Start-up and Operation under Gravitation," Proc. of 3rd Int. Heat Pipe Conf., pp. $2 i \div-282$. 
Table 1. Sumary of the boundary conditions for a matheatical model of the heat pipe start-up

\begin{tabular}{|c|c|c|c|c|c|}
\hline \multirow{2}{*}{\multicolumn{2}{|c|}{ 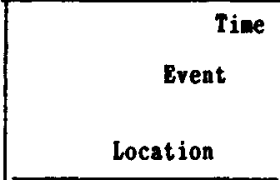 }} & 18t and 2nd periods & 3rd period & 4th period & 5th and 6th periods \\
\hline & & $\begin{array}{l}\text { heat transfer by } \\
\text { conduction; no liquid } \\
\text { notion; free } \\
\text { molecular flow }\end{array}$ & $\begin{array}{l}\text { solid and liquid states; liquid motion in } \\
\text { the wick; continuum flow in the part of the } \\
\text { vapor space }\end{array}$ & $\begin{array}{l}\text { no solid state of the vorking substance; } \\
\text { liquid notion in the vick; continuun flow } \\
\text { in the part of the vapor space }\end{array}$ & $\begin{array}{l}\text { liquid motion in the vick; continuun flow } \\
\text { in the entire vapor space; the heat pipe } \\
\text { approaches the steady state operation }\end{array}$ \\
\hline \multicolumn{2}{|c|}{$\begin{array}{l}\text { outer wall } \\
\text { surf ace }\end{array}$} & \multicolumn{4}{|c|}{$\left.r_{w} \frac{n_{w}}{\partial r}=q(x, t)+h_{c}\left(T_{c}-T_{w}\right)+o\right\}\left(T_{r}^{4}-T_{w}^{4}\right)$} \\
\hline \multicolumn{2}{|c|}{$\begin{array}{l}\text { wall and wick } \\
\text { structure interface } \\
\left(r=n_{w}\right)\end{array}$} & $\begin{array}{l}T_{w}=T_{i} \\
x_{w} \frac{\partial r_{w}}{\partial r}=r_{i} \frac{\partial T_{i}}{\partial r}\end{array}$ & $\begin{array}{l}T_{w}=T_{i} \\
r_{w} \frac{\partial i}{\partial r}=r_{i} \frac{\partial T_{i}}{\partial r} \\
v_{\ell}=v_{\ell}=0 \text { for } T_{i}>T_{w} \quad \text { (liquid region) }\end{array}$ & \multicolumn{2}{|c|}{ 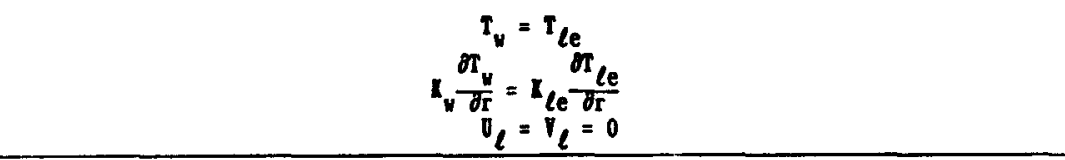 } \\
\hline \multicolumn{2}{|c|}{$\begin{array}{l}\text { liquid-vapor } \\
\text { interface } \\
\left(r=n_{v}\right)\end{array}$} & $\frac{\partial T_{i}}{\partial r}=0$ & 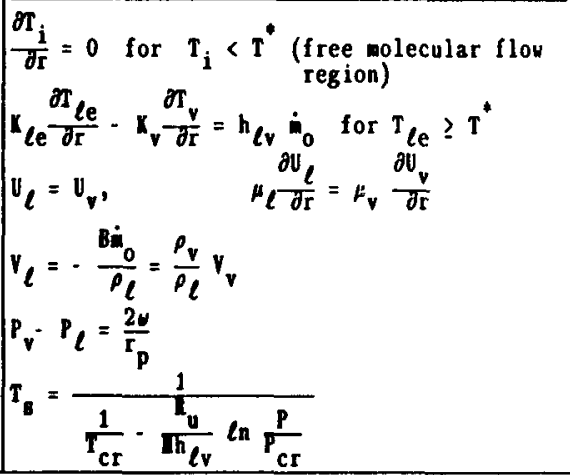 & 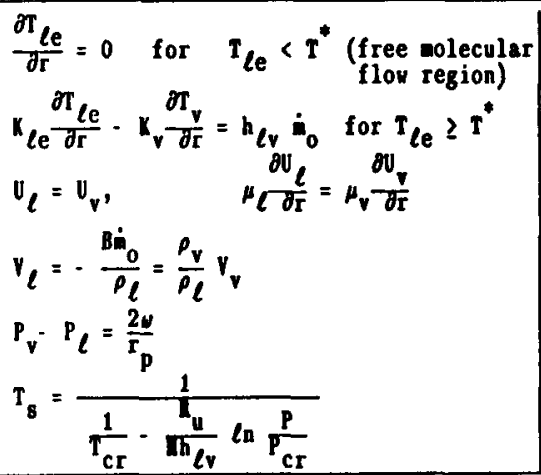 & 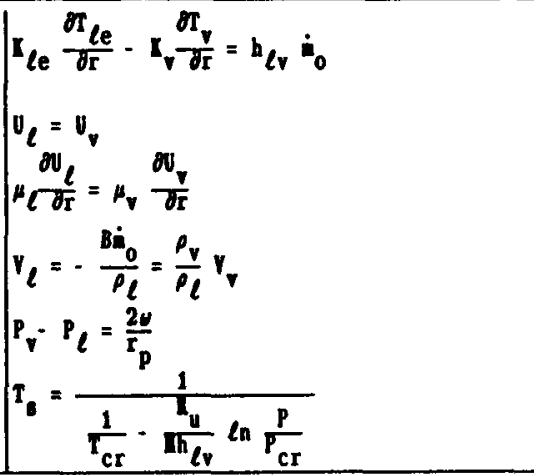 \\
\hline \multirow{3}{*}{$\begin{array}{l}\text { both } \\
\text { ends } \\
\text { of the } \\
\text { pipe } \\
(x=0, L)\end{array}$} & nell & \multicolumn{4}{|c|}{$\frac{\partial T_{w}}{\partial x}=0$} \\
\hline & $\begin{array}{l}\text { wick } \\
\text { structure }\end{array}$ & $\frac{\partial r_{i}}{\partial x}=0$ & $\begin{array}{l}\partial T_{i} \\
\partial x \\
U_{\ell}=V_{\ell}=0 \text { for } T_{i}>T_{m} \quad \text { (liquid region) }\end{array}$ & $\begin{array}{l}\frac{\partial \tau_{\ell}}{\partial x}=0 \\
v_{\ell}=v_{\ell}=\end{array}$ & \\
\hline & $\begin{array}{l}\text { vapor } \\
\text { space }\end{array}$ & $\begin{array}{l}\text { no boundary condition } \\
\text { is needed due to } \\
\text { free molecular flow }\end{array}$ & $\begin{array}{l}v_{v}=v_{v}=0 \text { for } T_{l e} \geq T^{*} \begin{array}{c}\text { (continuum flow } \\
\text { region) }\end{array} \\
\partial T_{v}=\frac{\partial P_{v}}{\partial x}=\frac{\partial \rho_{v}}{\partial x}=0 \\
\frac{\partial x}{x}=0\end{array}$ & & $\begin{array}{l}v_{v}=V_{v}=0 \\
\frac{\partial \tau_{v}}{\partial x}=\frac{\partial P_{v}}{\partial x}=\frac{\partial \rho_{v}}{\partial x}=0\end{array}$ \\
\hline \multicolumn{2}{|c|}{$\begin{array}{l}\text { centerline of } \\
\text { the pipe }(r=0)\end{array}$} & $\begin{array}{l}\text { no boundary condition } \\
\text { is needed due to } \\
\text { free molecular flow }\end{array}$ & $\begin{array}{l}v_{v}=0 \quad \text { for } \quad T \ell e \geq T^{*} \quad \begin{array}{c}\text { (continuum flow } \\
\text { region) }\end{array} \\
\frac{\partial \rho_{v}}{\partial \mathrm{r}}=\frac{\partial \mathrm{V}_{\mathrm{v}}}{\partial \mathrm{r}}=\frac{\partial \mathrm{E}_{\mathrm{v}}}{\partial \mathrm{r}}=\frac{\partial \mathrm{P}_{\mathrm{v}}}{\partial \mathrm{r}}=0\end{array}$ & & $\begin{array}{l}v_{v}=0 \\
\frac{\partial \rho_{v}}{\partial r}=\frac{\partial v_{v}}{\partial r}=\frac{\partial r_{v}}{\partial r}=\frac{\partial P_{v}}{\partial r}=0\end{array}$ \\
\hline
\end{tabular}




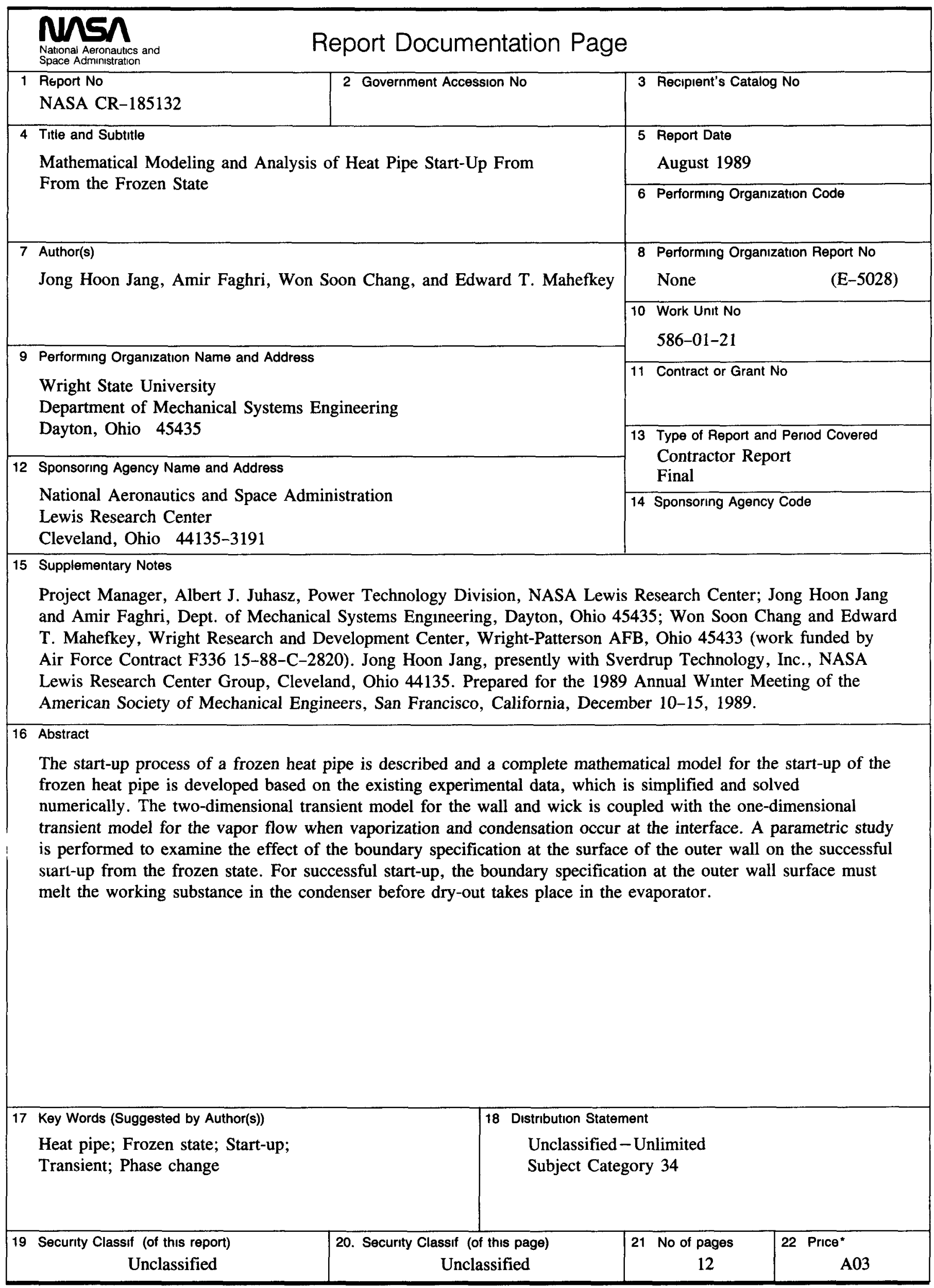


National Aeronautics and Space Admınıstratıon

Lewis Research Center

Cleveland. Ohıo 44135

Onictal Business

Penaity for Pitvate Use $\$ 500$
SECOND CLASS MAIL

ADDRESS CORRECTION REOUESTED

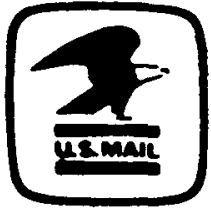

Postage and Fees Paid

National Aeronautics and

Space Adminustration

NASA-451 